\title{
AREA-WIDE MOSQUITO MANAGEMENT IN LEE COUNTY, FLORIDA, USA
}

\author{
E. W. FOLEY IV, R. L. MORREALE, D. F. HOEL AND \\ A. M. LLOYD \\ Lee County Mosquito Control District, 15191 Homestead Road, Lehigh Acres, \\ Florida 33971,USA; Hoel@lcmcd.org
}

\begin{abstract}
SUMMARY
Located in South Florida, the Lee County Mosquito Control District (LCMCD) is the largest single county mosquito abatement programme in the USA based on sheer necessity to combat the extremely high populations of mosquitoes found naturally in the area. South Florida is one of the largest, flattest, wettest, subtropical areas on the planet, making it prime habitat to produce enormous numbers of mosquitoes. LCMCD operates independently an integrated mosquito management (IMM) programme, funded by local taxation, which effectively and responsibly controls mosquitoes minimizing risk to human health, while reducing the environmental footprint. LCMCD incorporates a broad-based approach of control measures ranging from physical or mechanical control, to biological control, larviciding, and adulticiding, as well as mosquito and arbovirus surveillance, public education, and comprehensive evaluation of products and techniques. LCMCD also strives to be at the forefront of advancing technologies, such as the Sterile Insect Technique (SIT) and unmanned aerial systems to assist with the implementation of ongoing suppression efforts. LCMCD continues to be a leader state- and nation-wide with a focus on sound and effective mosquito control for the citizens of Lee County, Florida since 1958.
\end{abstract}

Key Words: Mosquito abatement programme, control district, integrated mosquito management (IMM), arbovirus surveillance, Aedes aegypti, Aedes albopictus, Aedes taeniorhynchus, Culex nigripalpus, Culex quinquefasciatus, Psorophora columbiae, Toxorhynchites rutilus rutilus, Gambusia holbrooki

\section{LEE COUNTY MOSQUITO CONTROL DISTRICT}

Mosquitoes have played a prominent role in Florida's history (Patterson 2004). The discovery that yellow fever, malaria, and dengue fever were mosquito-borne diseases prompted the formation of the Florida State Board of Health in 1889 and the establishment of the Florida Anti-Mosquito Association in 1922, followed shortly by legislation allowing the creation of mosquito control Special Taxing Districts (Connelly and Carlson 2009).

J. Hendrichs, R. Pereira and M. J. B. Vreysen (eds.), Area-Wide Integrated Pest Management: Development and Field Application, pp. 319-338. CRC Press, Boca Raton, Florida, USA.

(C) 2021 IAEA 
Lee County Mosquito Control District (LCMCD) was established as an independent taxing district in 1958 by an act of the Florida Legislature, and has been providing mosquito control services to the citizens of Lee County for over sixty years. Additionally, the Lee County Hyacinth Control District was formed by the Florida Legislature in 1961 to serve Lee County in controlling water hyacinth (Eichhornia crassipes), water lettuce (Pistia stratiotes), both mosquito-breeding plants, and other noxious aquatic weeds impeding navigation in the Caloosahatchee River and within other water bodies located in Lee County.

Both the mosquito and hyacinth control districts are situated at the same physical location and governed by the same seven-member board of commissioners; commissioners are elected to serve a four-year term. Both independent districts collect ad valorem taxes needed to perform their respective control activities. LCMCD is governed according to the laws of Florida, Statue Chapter 388 and the rules of the Florida Department of Agricultural and Consumer Service Administration Code 5E/13. Act 98-462, Laws of Florida, is the enabling legislation creating Lee County Hyacinth Control District. The districts are led by a single executive director.

Lee County Mosquito Control District is the largest single county mosquitoabatement district of more than 700 districts and programmes in the USA, of which 66 are in Florida (Challet 1994; McKenna 2016; Kerzee 2019). With an annual budget of ca. USD 24 million, LCMCD has remained at the forefront of mosquito control by helping to develop control technologies that are effective and sensitive to Florida's unique natural habitats and wildlife. Over 97 per cent of Lee County's mosquitoes are controlled by LCMCD, the rest are controlled by the Ft. Myers Beach Mosquito Control District, formed in 1949 by referendum election for the purpose of providing mosquito control for the town of Ft. Myers Beach. The creation of Ft. Myers Beach Mosquito Control District precedes the formation of LCMCD by nine years.

Lee County, Florida is located in the south-eastern USA on the south-western coast of Florida (Fig. 1). Bordered by the Gulf of Mexico on the west, Charlotte County to the north and Collier County to the south. Lee County is known for its popular white sandy beaches and its large estuary habitat at the base of the Caloosahatchee River. With over 56000 acres (22 662 ha) of salt marsh mangrove habitat and several large, populated barrier islands, Lee County is unique in the scale of mosquito breeding habitats that are in close proximity to urbanized environments.

\subsection{Conservation and Land Management Agencies}

As concern for conservation increases, a large portion of land in Lee County is protected by various land management agencies, such as the Florida Department of Environmental Protection (FDEP), the Florida Fish and Wildlife Conservation Commission (FFWCC), the U.S. Fish and Wildlife Service (USFWS), and the Environmental Protection Agency (US-EPA) (Connelly and Carlson 2009). LCMCD collaborates with several local, state, and federal land managers to conduct mosquito abatement activities on these lands (Fig. 2). Due to the biodiversity and individual geographic challenges, many of these lands have their own individual management requirements and restrictions pertaining to mosquito abatement (Batzer and Resh 1992). 
To better work together towards a common goal, LCMCD holds annual meetings each spring with all land managing agencies to discuss any issues brought forth from the previous year. During this time, future projects and operations are discussed as a way to develop future operations and build working relationships between agencies and LCMCD.

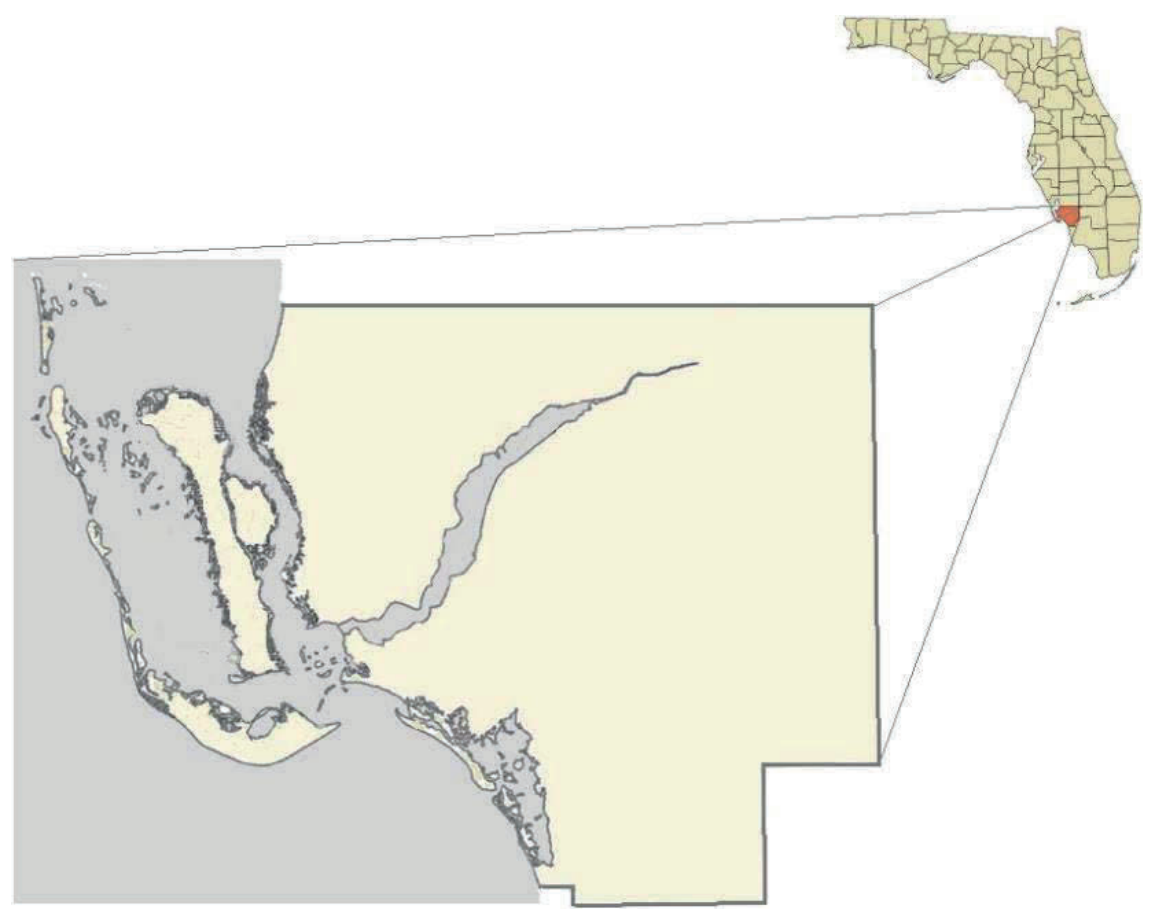

Figure 1. Map showing the location of Lee County in south-western Florida, USA.

\subsection{Public Education}

As Lee County is one of the counties with the fastest growing human population in the USA, LCMCD dedicates significant resources to educate the public concerning the importance of a strong mosquito abatement programme and why it is needed to live comfortably in south-western Florida. LCMCD believes in strong community engagement and participates in public outreach events throughout the year.

LCMCD also aims to produce a more informed community through a hands-on approach by collaborating with the local Lee County School District and employing a team of licensed educators. LCMCD has developed a unique working relationship with the local school district to fund licensed teachers that offer courses in the school district classrooms across the county teaching mosquito biology and mosquito control essentials to students from kindergarten through high school. All curricula follow the most current standards put forward by the state of Florida and engages students in real world science focused on mosquito control. This instrumental programme gets 
students excited about science at an early age. LCMCD teachers developed coursework that incorporates biology, ecology, and chemistry with mosquito control, helping the students recognize the science behind what it takes to control mosquitoes. The result is an educated Lee County population, knowledgeable of mosquito control, understanding of why operations occur, the environmental protections in place and judicious use of insecticides.

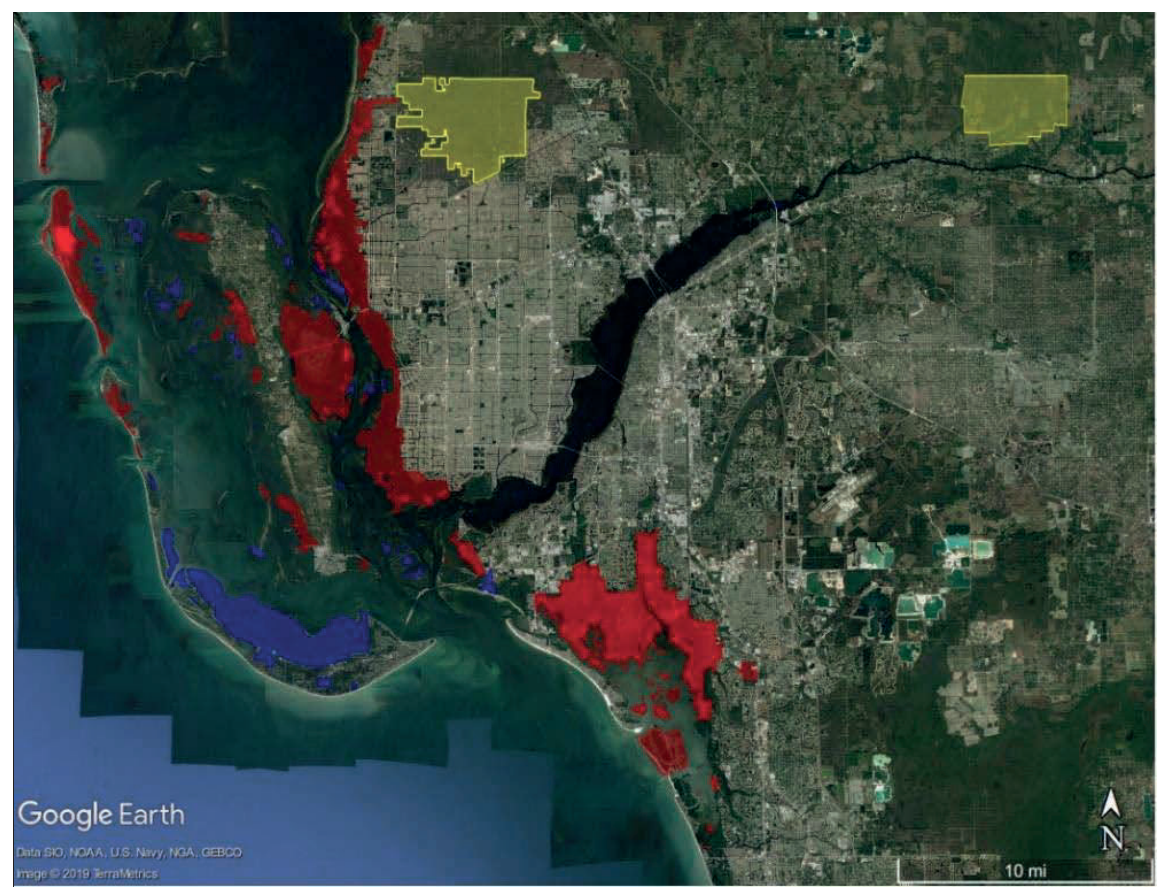

Figure 2. Map of land managing partners in Lee County, Florida. Red represents FDEP lands, blue represents USFWS lands, and yellow represents FFWCC lands.

\subsection{Primary Mosquito Species}

The black salt marsh mosquito, Aedes taeniorhynchus (Wiedemann) (Agramonte and Connelly 2014), reproduces in extremely high numbers in the 56000 acres of protected salt marsh within LCMCD (Fig. 3). The aquatic habitat for this species is vast and covers a significant portion of LCMCD's 450000 acres $\left(1821 \mathrm{~km}^{2}\right)$. This species is known to oviposit up to 45000 eggs per square foot $\left(0.1 \mathrm{~m}^{2}\right)$ (Provost 1969) and is capable of autogeny, the ability to lay an initial batch of eggs without the benefit of a blood meal, believed to be a survival mechanism when hosts are scarce. After developing into adults, Ae. taeniorhynchus fly from 20 to 30 miles (32.2 to $48.3 \mathrm{~km}$ ) in search of a blood meal. It is an aggressive biter and is a major pest along the coastal areas of LCMCD, primary being a nuisance biter and a vector of dog heartworm (Dirofilaria immitis Leidy) (Nayar and Connelly 2017), as well as a potential vector for eastern equine encephalitis (EEE) (Agramonte and Connelly 2014). 
High tides that flood coastal marsh areas and summer rains cause explosive production of these Ae. taeniorhynchus mosquitoes. With a potential of 2 billion eggs per acre $(0.4 \mathrm{ha})$, managing this mosquito on an area-wide basis over the large salt marsh surfaces is of great importance.

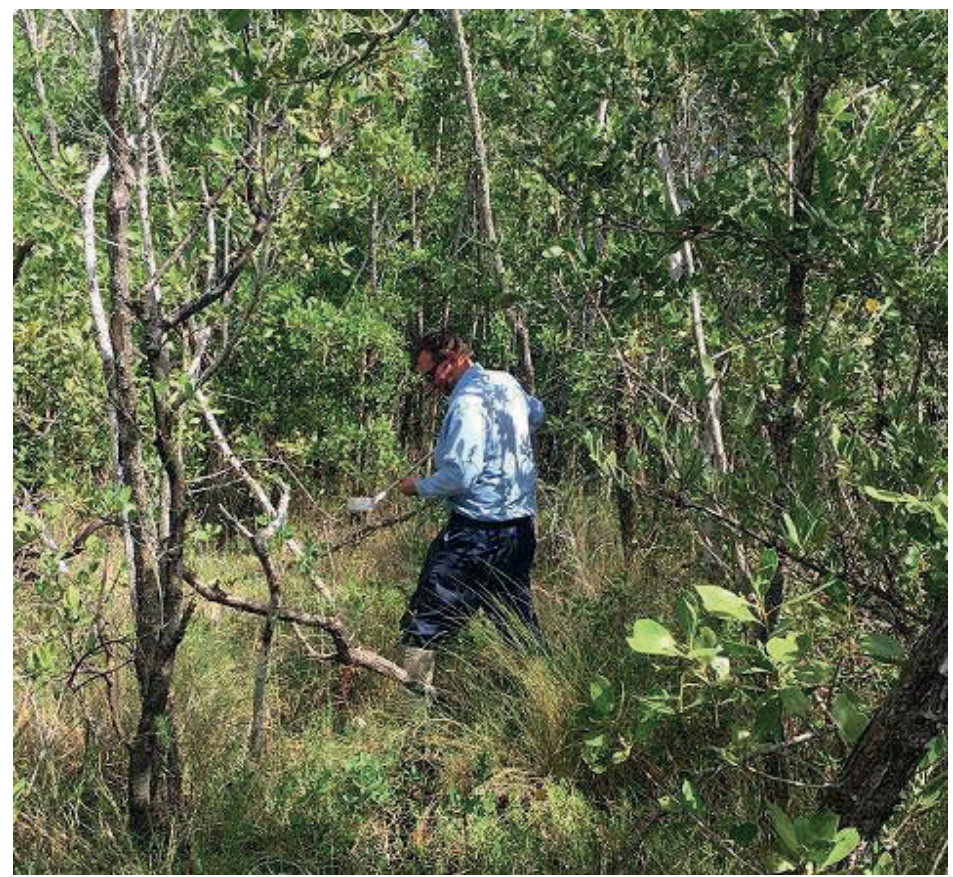

Figure 3. Inspector, Sean Christman, searches for Ae. taeniorhynchus larvae in salt marsh habitat.

Culex nigripalpus Theobald is a freshwater species with larvae found in roadside ditches, retention/detention ponds, agricultural fields and flooded areas (Day 2017). These sites develop more decomposing organic material later in the rainy season that become increasingly attractive to these mosquitoes. This species is responsible for the transmission of Saint Louis encephalitis and West Nile virus (Day and Curtis 1999). CX. nigripalpus is a major health threat to residents of LCMCD and is a priority for control.

Culex quinquefasciatus Say, the southern house mosquito, is a freshwater species most notable for their association with residential habitats and can be readily found in Lee County (CABI 2019). Similar to Cx. nigripalpus, this species can be found in roadside ditches as well as storm drains, containers, and other sites with high organic matter. In contrast to $C x$. nigripalpus, the larvae of this species are able to survive in waters with higher levels of pollution. Cx. quinquefasciatus is the primary vector for St. Louis encephalitis virus throughout the southern USA as well as a potential vector for West Nile virus (Hill and Connelly 2009). 
Aedes aegypti (L.), the yellow fever mosquito, is a dusk and dawn biting species, which can also be found biting during the daytime in the shade. This species is closely associated with natural and artificial containers (Zettel and Kaufman 2019). Females have a relatively short flight range $(100-500 \mathrm{~m})$ (McDonald 1977; Muir and Kay 1998) and are typically found close to a nearby water source. This species is responsible for the transmission of several disease agents such as yellow fever, dengue, chikungunya and Zika viruses. Ae. aegypti is a health threat to residents of LCMCD and is a priority for control.

Psorophora columbiae (Dyar \& Knab) is a pestiferous freshwater species (Bibbs et al. 2019). It is found extensively throughout the county in roadside ditches, retention/detention ponds, irrigated agricultural fields, pastures, and low-lying areas that regularly flood, both within and surrounding LCMCD. A floodwater mosquito, it is produced in large numbers as water levels rise and low areas flood during the rainy season and is a major nuisance in the inland areas of LCMCD.

Other nuisance species that sometimes occur in high numbers include Psorophora ferox Humboldt, Ps. ciliata Fabricius, Anopheles quadrimaculatus Say, An. atropos Dyar \& Knab, An. cruicians, Mansonia titillans (Walker), Mn. dyari Belkin, Heinemann \& Page, Aedes albopictus (Skuse), and others.

\subsection{Weather}

Lee County has a subtropical climate, distinguished by warm humid weather yearround, with minimal temperature differences between seasons. Mosquito production in southern Florida is dependent on the presence of standing water throughout the year. Even during the dry winter season, temperatures are rarely sustained low enough to prevent larval development or cause mortality in adults. Seasonal summer rains begin in May or June in south-western Florida and continue through September or October. While the average annual rainfall per year is 53 inches $(1.35 \mathrm{~m})$, this amount can be exceptionally variable, especially after hurricanes or tropical storms, and contributes to mosquito production year-round. Rainfall totals and tidal activity are monitored all year with increased monitoring throughout the summer months.

\section{SURVEILLANCE}

\subsection{Population Surveillance}

Due to south-western Florida's subtropical climate and mild winters, mosquito surveillance is conducted year-round with increased mosquito collections in the summer months. To address the over 45 mosquito species present in Lee county, an illustration of the nuisance problem being faced, LCMCD deploys multiple trap systems that include eighteen Centers for Disease Control and Prevention (CDC) light traps (Kline 2006; AMCA 2017), seven Biogents BG-Sentinel traps (Regensburg, Germany) (Rose et al. 2006; AMCA 2017), and 6 trap trucks (Fig. 4) to survey 54 pre-determined routes for collecting mosquitoes in flight. CDC and BGS traps are set on a weekly basis, while the trap trucks operate across the county every night from early May through 30 October. 
CDC light traps are baited with carbon dioxide in the form of dry ice blocks and set for two trap nights/week. Trap collections are identified the following morning. BGS traps are utilized in urban/suburban areas once per week for Ae. aegypti and Ae. albopictus surveillance. Along with carbon dioxide, these traps are baited with octenol lures, as well as proprietary BG-lures. BGS traps are very effective in collecting these day-biting mosquitoes.

LCMCD conducts a one-step, Triplex Real-Time PCR (polymerase chain reaction) assay on Ae. aegypti and Ae. albopictus mosquitoes collected in the weekly BGS trappings. Collected mosquitoes are tested biweekly for the presence of dengue virus, chikungunya virus, and Zika virus.

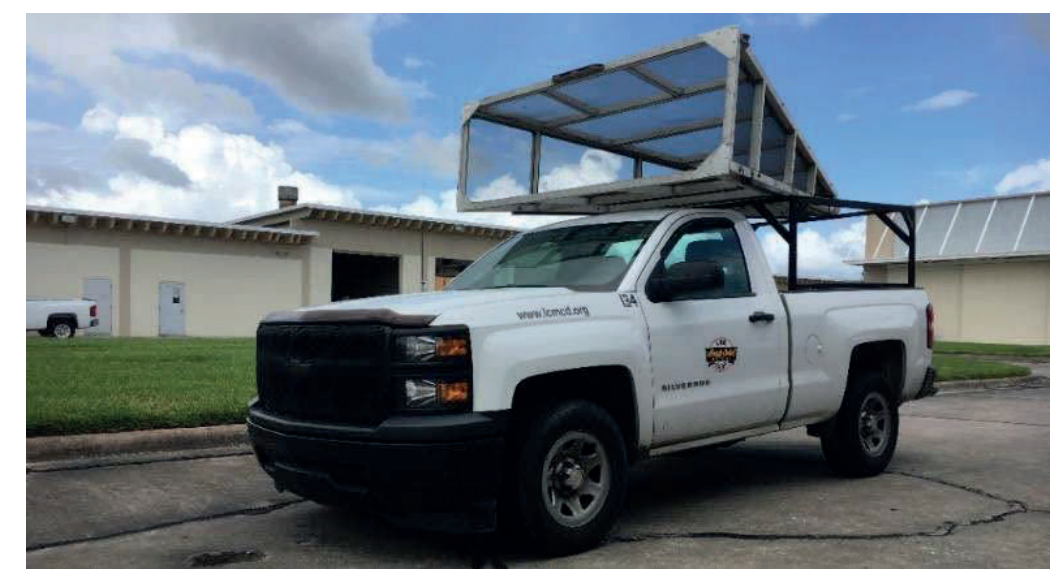

Figure 4. Trap truck for collecting mosquitoes in flight along pre-determined routes.

Between the months of May and October, LCMCD operates an extensive trap truck programme. An LCMCD trap truck consists of a large conical shaped collection screen $(7$ feet $(2.13 \mathrm{~m})$ wide by 2.5 feet $(0.76 \mathrm{~m})$ tall) affixed atop a vehicle (Fig. 4). The trap body measures 11 feet $(3.35 \mathrm{~m})$ long and tapers rearward to a 6 by 6 -inch $(15$ by $15 \mathrm{~cm}$ ) outlet at the rear of the vehicle. At the start of each predetermined route, a collection bag is secured over the collection screen outlets. Routes are driven at a speed of 20 miles $(32.2 \mathrm{~km})$ per hour for a three-mile $(4.8 \mathrm{~km})$ run and bags collected immediately after finishing. Rainfall gauges are stationed at the beginning and ending locations of each route, providing additional precipitation data important to mosquito production.

\subsection{Arbovirus Surveillance}

LCMCD maintains 16 sentinel chicken coops stationed around the county for the purpose of monitoring arbovirus transmission (Fig. 5). Six birds are kept at each location with blood samples taken once every two weeks and sent to the Florida Department of Health Laboratory in Tampa for analysis. 


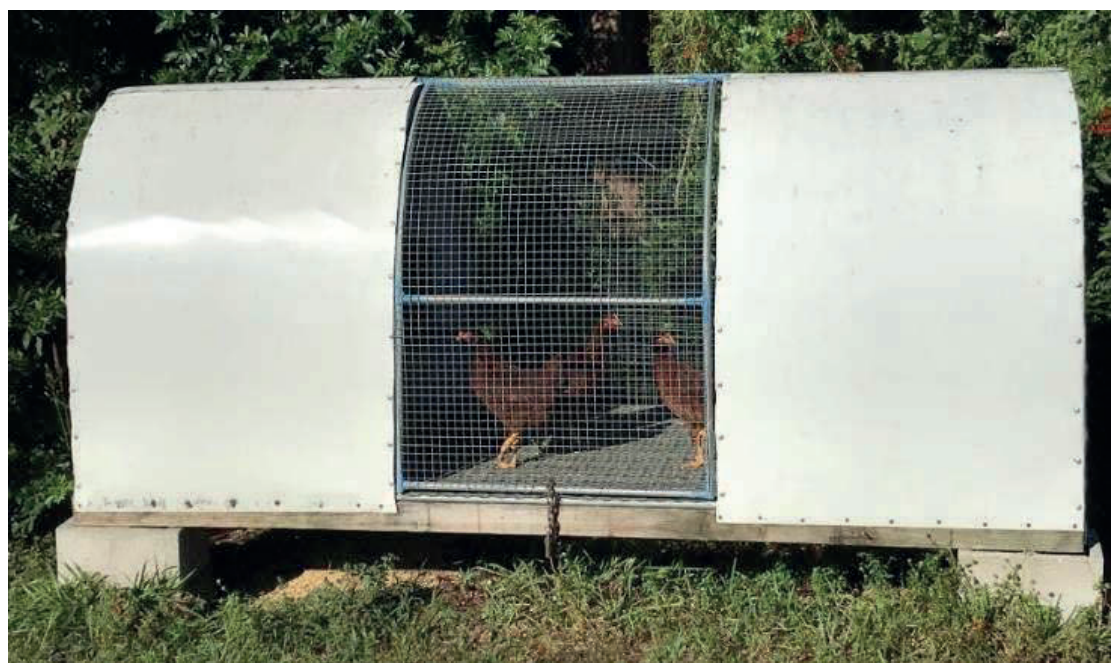

Figure 5. Sentinel chicken coop on location.

Blood is collected over the course of two days and processed in the LCMCD laboratory prior to shipping to the state laboratory. Half of each processed blood sample is reserved for in-house ELISA testing separate from the state laboratory. Testing samples independently allows for a quicker turnaround time for operational response if a location indicates the presence of an arbovirus. However, the samples sent to the state laboratory are considered the official record of arbovirus detection for the state.

\subsection{Landing Rates}

Landing rates are an effective and quick tool to determine the scale of a mosquito problem in a specific area (Connelly and Carlson 2009; AMCA 2017). Measuring landing rates involves an inspector visiting a citizen complaint location and counting the number of host-seeking adult mosquitoes within a sixty-second period. This relativity simple technique allows for a good understanding of mosquito bite pressure in an area. The landing rate surveillance method allows a single inspector to cover a larger geographic area more efficiently than setting collection traps overnight.

\subsection{Service Request Calls}

Concerned citizens are encouraged to call our office and enter a request for service if they are experiencing a mosquito problem at their residence. LCMCD logs all of the calls into our database and uses them as another form of surveillance. Citizens are also able to enter a request through our website (LCMCD 2019) rather than calling directly if they prefer. By mapping the callers address into our geographic information systembased data management programme, LCMCD is able to use these requests as a way to view problematic areas and dispatch inspectors accordingly. 
Inspectors responding to individual calls make every effort to meet with the callers directly and search for mosquito problems on their property. If mosquito breeding is found, the inspectors take the time to educate the homeowner on proactive steps they can take to limit future problems. Inspectors log their findings on laptop computers before moving onto the next site. Service request calls sometimes identify areas needing treatment.

\subsection{Field Validation}

Field validation at LCMCD is a comprehensive programme designed to evaluate new products and technologies, monitor for the development of insecticide resistance and conduct droplet size characterization on all adulticiding equipment used. The field validation programme also maintains laboratory colonies of four different mosquitoes to include the locally pestiferous or disease vectoring species of Ae. taeniorhynchus, Cx. quinquefasciatus, Ae. albopictus, and Ae. aegypti.

In addition, the field validation programme maintains colonies of the predatory mosquito Toxorhynchites rutilus rutilus (Coquillett) and the predatory mosquito fish Gambusia holbrooki Girard that are used for biological control of larval mosquitoes; it also oversees the releases of these predators.

LCMCD conducts bioassays on both larval and adult mosquitoes to evaluate product efficacy in controlling local mosquito populations. Products used to control adult mosquitoes are evaluated using the CDC bottle bioassay protocol (Connelly and Carlson 2009). Products used to control larval mosquitoes are evaluated using a serial dilution larval assay (WHO 2016). Laboratory colony susceptibilities are compared against results of wild mosquitoes to establish a control baseline.

The field validation programme is responsible for conducting droplet characterization on all adulticiding spray systems annually to ensure equipment is in proper working order prior to use. Droplet characterization is conducted using one inch $(2.54 \mathrm{~cm})$ and three-millimetre Teflon-coated slides to capture droplets for analysis. Using automated computer software, the slides are analysed under a compound microscope to determine droplet Volume Median Diameter (VMD) (Connelly and Carlson 2009). Droplet sizes must fall within an acceptable range as determined by product label and approved by EPA. Droplet characterization is conducted any time an adulticiding spray system is altered with a minimum of once per year to ensure the equipment is working properly before use.

Additionally, the field validation programme evaluates new products prior to their incorporation into field operations. New product formulations are first evaluated under laboratory conditions to establish the appropriate application rate under ideal conditions. Products with favourable laboratory results are then applied in small-scale field sites for possible operational selection. During these trials, products are monitored for efficacy, duration, and any potential adverse effects to local non-target species. These trials are crucial to determine how a product is going to work under local conditions prior to their implementation as part of the LCMCD treatment programme. 


\section{BIOLOGICAL CONTROL}

Biological control is a vital component of an integrated mosquito management (IMM) programme of any size. Therefore, LCMCD also incorporates biological methods for mosquito control to minimize the use of insecticides. LCMCD accomplishes this by introducing the predatory native mosquito fish ( $G$. holbrooki) into mosquito breeding areas (Cassiano et al. 2018) and releasing the predatory mosquito Tx. rutilus rutilus (Focks et al. 1980).

In addition, mosquito ditches were installed throughout the 1960s as a form of water management that provides access of natural predators into mosquito breeding habit during times of high tides (Fig. 6). When water levels rise during a high tide, these ditches can introduce juvenile fish species into areas that otherwise would have been inaccessible. As water levels recede these species make their way back to the safety of the ditches.

LCMCD has a mosquito fish programme designed to raise native $G$. holbrooki for release into problematic areas (Fig. 7). In 2019, LCMCD released around one thousand fish into various sites with the goal of natural larval suppression. Gambusia is a native freshwater genus of fish that are ferocious predators of mosquito larvae. Often, once this species establishes breeding populations in a body of water, they will suppress mosquito larvae to levels where insecticides are no longer needed.

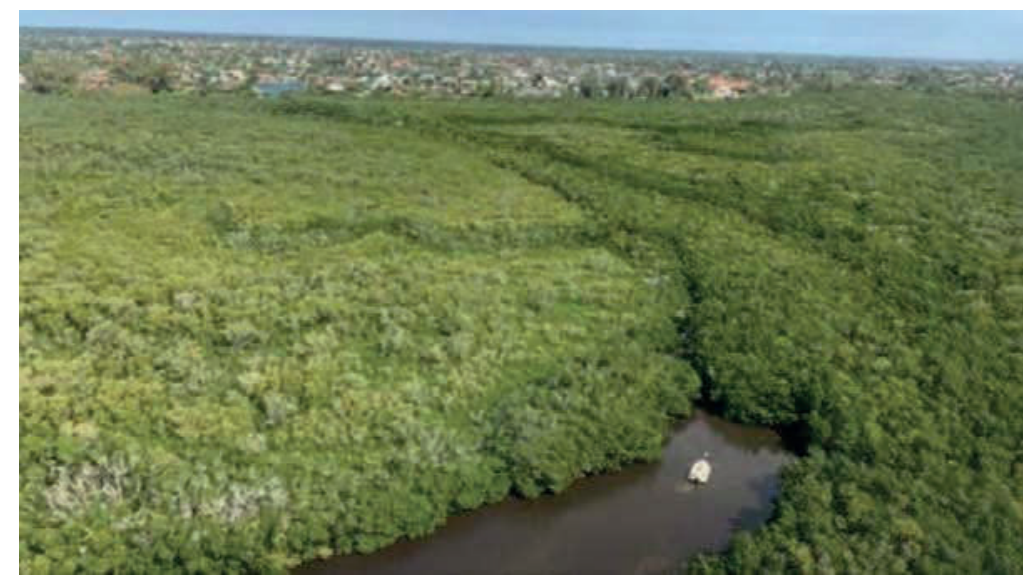

Figure 6. Network of mosquito ditches on Pine Island, Florida. Darker green foliage shows area where ditches are present.

LCMCD also maintains a colonized population of Tx. rutilus rutilus for the purpose of biological control. Native to south-western Florida, these beneficial mosquitoes are predatory on other mosquito larvae and adults do not require a blood meal for reproduction (Focks et al. 1980). By introducing these beneficial mosquitoes into isolated habitats, such as abandoned properties and cemeteries, the goal is to promote the natural suppression of sanguivorous mosquito species. 


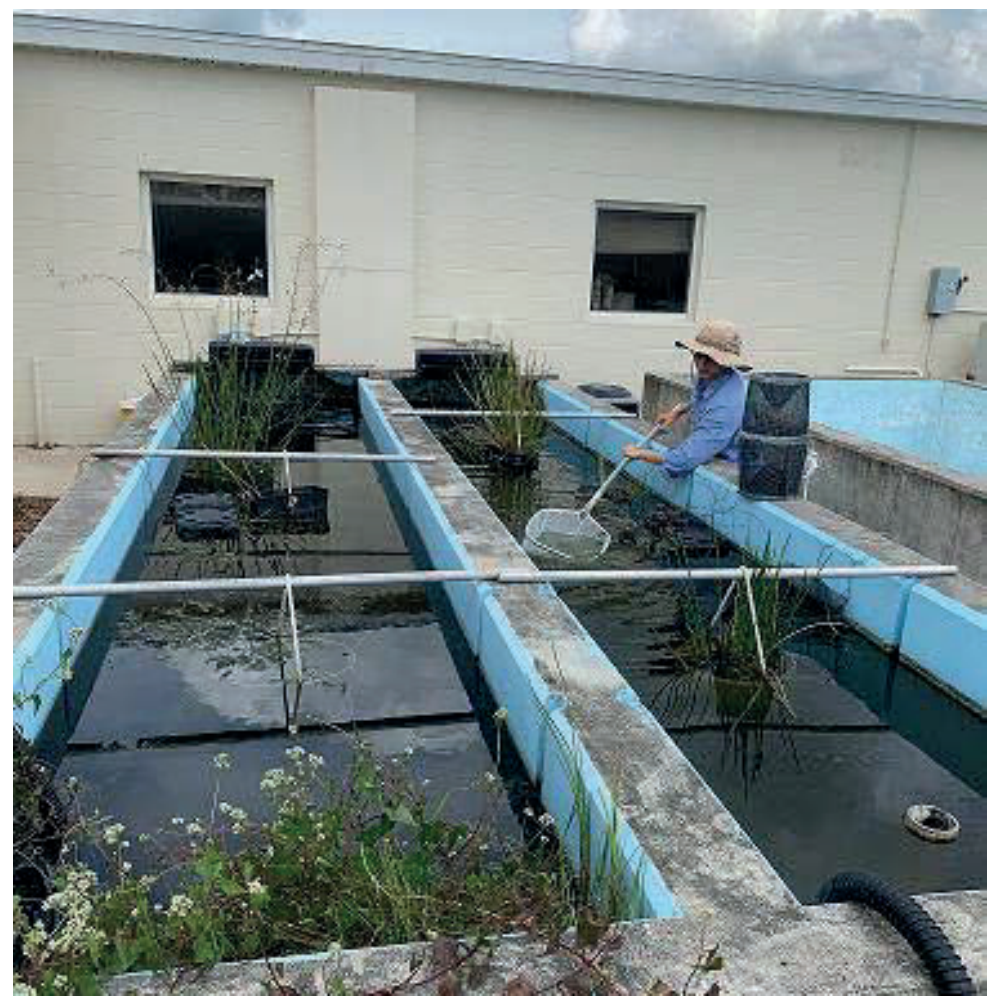

Figure 7. Biologist, Kara Tyler-Julian, tends to Gambusia fish rearing tanks.

\section{MOSQUITO BREEDING SOURCE REDUCTION}

Source reduction is an important component of an IMM programme. LCMCD inspectors work in the field everyday surveying for larvae. When appropriate, all known larval sources are inspected to determine if the breeding site can be reduced or eliminated before considering chemical and biological treatment methods. This can include, but is not limited to, filling-in tree holes, dumping buckets/containers, removing waste that holds water, drilling holes to drain containers, placing screen covers over rain barrels, etc.

Shortly after LCMCD was established in 1958, crews began work installing mosquito drainage ditches across much of its salt marsh habitat. Digging was accomplished via dragline machinery to depths of five by six feet $(1.52$ by $1.83 \mathrm{~m})$ wide. By the early 1970s, LCMCD had installed a complex network of canals through much of its problematic coastal areas with the purpose of removing water from the marsh during periods of low tide. By allowing water a place to recede naturally, it limits mosquito breeding habitat and greatly reduces the amount of pesticide needed for control. Although these ditches were installed up to sixty years ago, they continue to function as designed and remain a valuable mosquito control tool in Lee County (Fig. 8). 


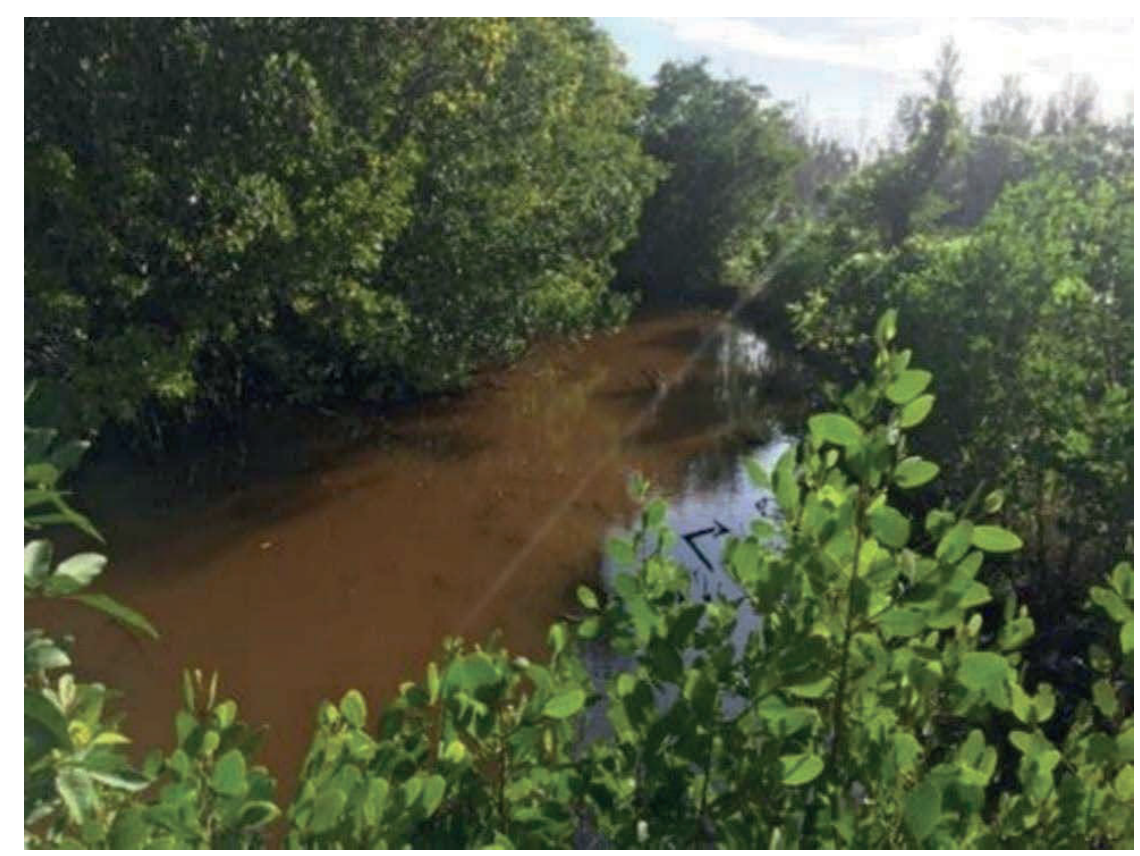

Figure 8. Mosquito ditch on Pine Island, Florida.

LCMCD continues to implement manual control methods in areas where applicable. Recently, LCMCD collaborated with the National Wildlife Refuge (NWR) of the USFWS to control mosquitoes on a remote island used as an active rookery for several species of shore birds. A depression in the interior of the island would fill with water in the summer months and breed Ae. taeniorhynchus mosquitoes. Due to the sensitive nature of nesting birds, getting access to inspect and treat the island was virtually impossible. In 2017, crews from the NWR and LCMCD met at the remote island and hand dug a ditch from the exterior of the island towards the problematic interior. In a couple of hours, a mosquito ditch was installed that drained the stagnant water from the interior of the island. During a high tide, the ditch can introduce natural predators such as fish and other macroinvertebrates into the ecosystem. As the tide retreats, the natural predators leave the island along with the water and mosquito larvae, virtually eliminating mosquitoes naturally.

\section{LARVAL MOSQUITO CONTROL}

\subsection{Ground Larviciding}

The ground larviciding programme at LCMCD focuses mainly on inland roadside ditches and residential neighbourhoods. Although some areas are affected by tidal fluctuations, most of ground larviciding is conducted in response to rainfall events for freshwater mosquito species. Ground larviciding crews survey areas of recent rainfall and treat with a variety of methods including a truck-mounted spray system, handheld 
equipment (backpack unit or squirt bottle) or single use treatment items (water-soluble pouches or briquette-formulated larvicides).

Vehicle-mounted spray systems (Fig. 9) primarily utilize products with the active ingredient temephos for larval control.

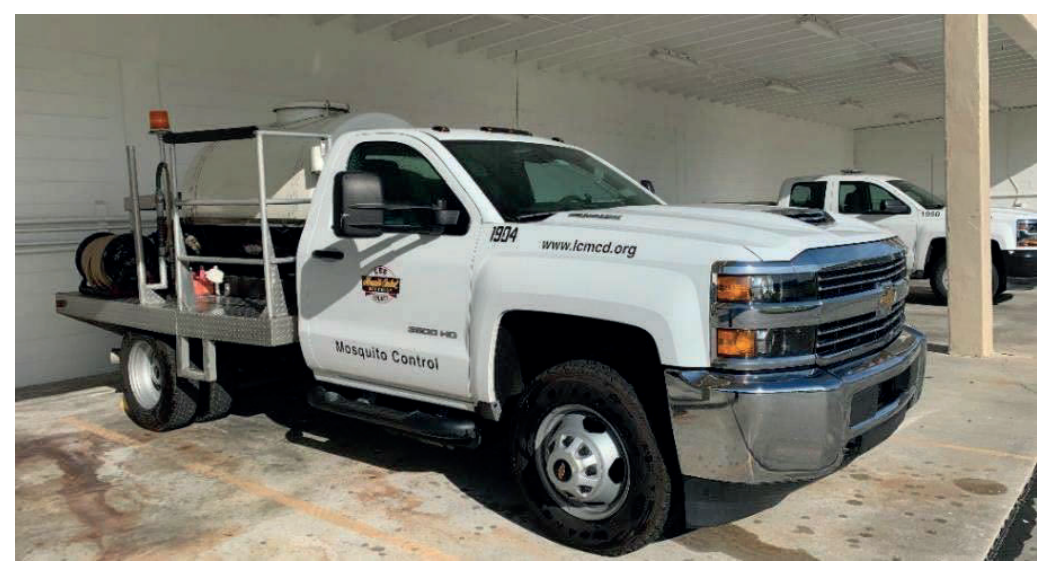

Figure 9. Vehicles used for ground larviciding.

Products dispensed with handheld equipment ranges widely depending on the situation, but mostly consists of monomolecular films, larviciding oils, and Lysinibacillus (Bacillus) sphaericus. Various formulations of L. sphaericus, spinosad, and methoprene products are available for single use treatment items ranging from 30 to 150 days of residual control and are used to treat more permanent bodies of water that will be problematic throughout the season. Bacillus thuringiensis is seldom used in ground larviciding operations, but it is commonly used in aerial larviciding operations at LCMCD.

All ground larviciding vehicles are equipped with a Global Positioning System (GPS) monitoring device to record vehicle location and speed. This system also records the activity of the vehicle-mounted spray system. All inspection and treatment information is recorded by the technician onsite with a laptop computer.

In the dry season, ground larviciding crews continue to survey for mosquitoes often found in breeding sites such as containers, tyres, and neighbourhood drainage basins. Without the consistent summer afternoon rains to flush these habitats, Culex species become established and cause problems for nearby residences. Consistent surveillance and treatment are critical to control mosquitoes in urbanized ecosystems.

To address more cryptic mosquito habitats with limited inspector access, LCMCD uses a truck-mounted A1 mist sprayer (A1 Mist Sprayers Resources, Inc., Ponca, Nebraska, USA). By driving residential roadways in the evening hours, this unit treats for mosquito larvae by blowing small droplets of liquid larvicide upwards of 50 feet $(15.24 \mathrm{~m})$ into the air enabling it to drift into residential areas that would otherwise be difficult to access. LCMCD has integrated this technique as a way to efficiently treat for mosquito larvae that otherwise would require a team of individuals going door-todoor to inspect and treat cryptic breeding sites in areas that may have limited access. 


\subsection{Aerial Larviciding}

Impoundments are areas of salt marsh surrounded by a dike to allow control of water levels for mosquito control, thereby negatively affecting wetland function and vegetation (Rey and Rutledge 2006). Even though Lee County is unique in having over 56000 acres of mangrove salt marsh habitat, little of it is managed through the use of impoundments, as is more common in other parts of the state. This habitat is home to several species of mosquitoes, most notably Ae. taeniorhynchus. This species is a ferocious biter and a prolific breeder with an extensive flight range that extends across the county (Provost 1952; Elmore Jr. and Schoof 1963). To best target these mosquitoes, LCMCD operates a robust aerial larviciding programme aimed at controlling these mosquitoes at their source while in their juvenile life stage.

LCMCD owns and operates a fleet of six Airbus (Herndon, Virginia, USA) H125 helicopters for the purpose of accessing and treating remote breeding sites (Fig. 10). LCMCD biologists constantly monitor salt marsh habitat for rainfall and tidal fluctuations throughout the year. Following a high tide or rain event, biologists fly to remote landing sites to inspect the new water for the presence of newly hatched juvenile mosquitoes. They will take various water samples around a geographic area and check for the presence of mosquito larvae. If larval densities exceed individual site thresholds, biologists record inspection data and schedule the area for treatment.

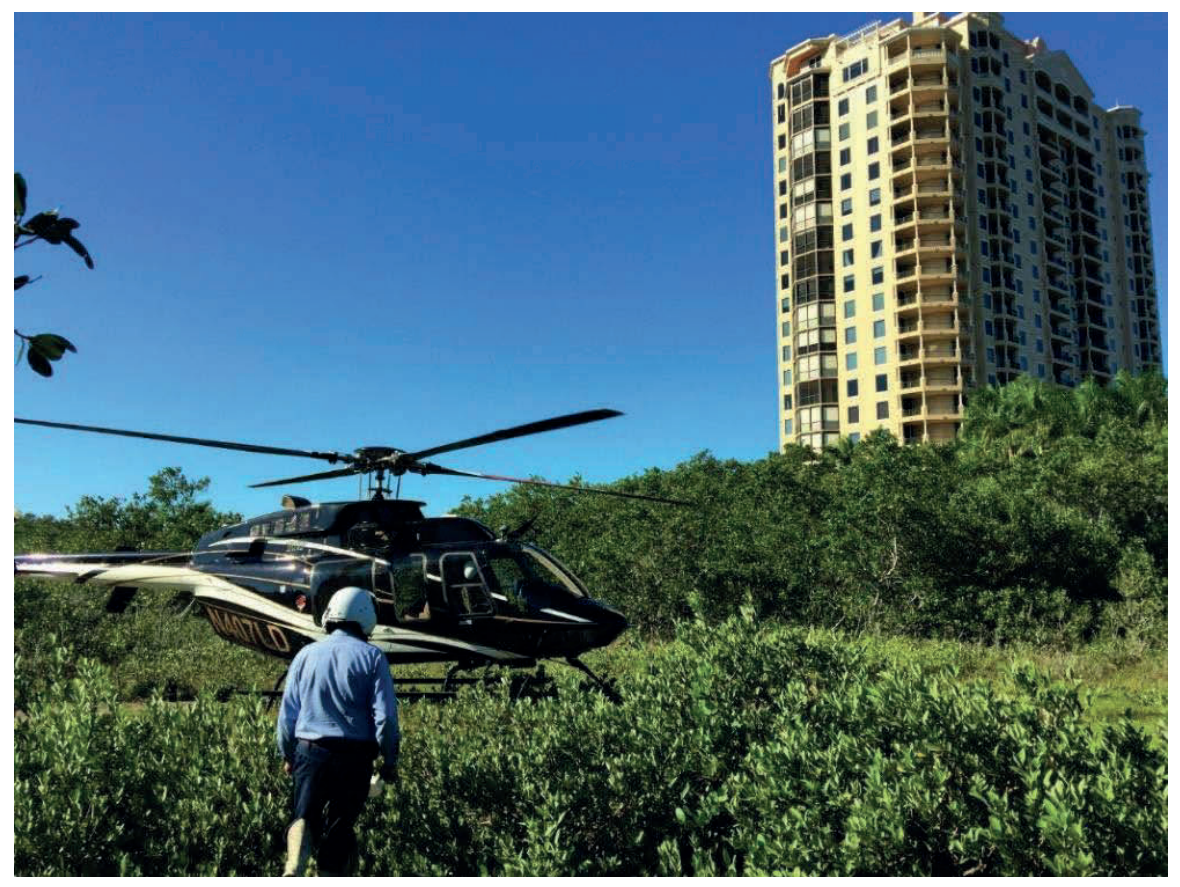

Figure 10. LCMCD Inspector searching for mosquito larvae in salt marsh habitat. 
Treatments are conducted once the biologists are able to develop a site-specific treatment plan, often as soon as that same day. LCMCD also owns eight remote heliport locations along the western edge of the county bordering salt marsh habitat. These locations serve as secure outpost facilities to refuel and reload products onto helicopters in areas closest to treatment sites. Computers equipped at these locations give biologists the ability to develop treatment plans on site without the need to return to LCMCD. Depending on site-specific needs, a variety of products are available for use, including temephos, B. thuringiensis israelensis, L. sphaericus, spinosad, methoprene, and larviciding oil. Product formulations also range from liquid to granular formulations as well as single use products providing 30-day residual control.

All helicopters are equipped with an on-board computer to control the helicopters' spray system. This system works harmoniously to upload the individualized treatment polygons with spraying turning on when the helicopter flies into the targeted polygon. Once the pilot exits the pre-programmed treatment zone, the spray system turns off. This GIS-based system operates with pinpoint accuracy that increases pilot safety by simplifying inflight procedures and prevents spraying of off-target sites, saving insecticide and money.

Following a treatment, biologists will return to their inspection site to complete a post-treatment inspection. All inspection data are recorded onsite at time of collection with a custom iPhone application. Once synchronised, all data are available for viewing at the office and are recorded in an organized format. All treatment data are captured by the system's on-board computer and are available for viewing posttreatment in a similar fashion.

\section{ADULT MOSQUITO CONTROL}

\subsection{Ground Adulticiding}

LCMCD operates 13 vehicles equipped with ultra-low volume (ULV) spray systems used to target adult mosquitoes in and around neighbourhoods (Fig. 11). Ground adulticiding missions are conducted between sunset and 02:00 to target flying mosquitoes when they are most active. Formulated products are applied without dilution or mixing, and equipment is calibrated to treat a 300 -feet (91.4 m) swath at a speed of 10 miles $(16.1 \mathrm{~km})$ per hour. A variable flow spray system is equipped to keep the targeted application rate even when the vehicle speed increases or decreases from the 10 miles per hour targeted spray rate. As the vehicle changes speed, within a range of 2-20 miles (3.2-32.2 km) per hour, the appropriate amount of product is dispensed according to label directions. When the vehicle speed surpasses 20 miles per hour, the spray system shuts off preventing spray. 


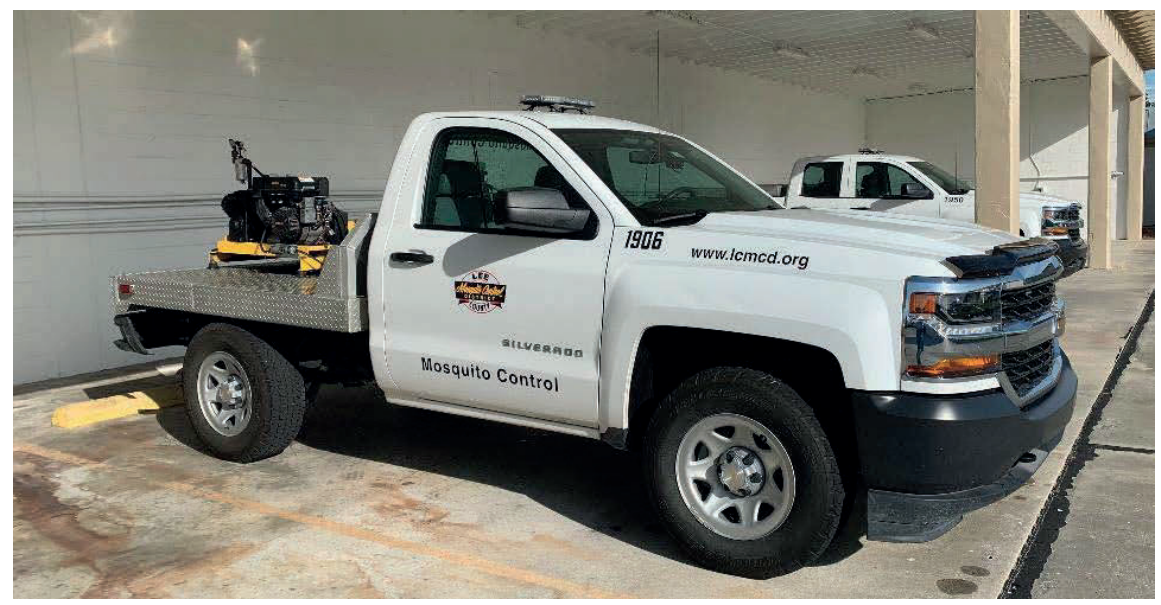

Figure 11. Ground adulticiding vehicles with rear-mounted ULV machine.

The vehicle's spray system is operated remotely from inside the cab of the vehicle with a handheld controller. This design prevents the driver from coming into contact with chemicals during spray operations and limits exposure. The spray system also records various parameters throughout the evening such as vehicle speed, vehicle location, spray activity, miles sprayed, acres treated, and total chemical dispensed. Chemical usage information is compared each morning to the amount recorded by the driver at the start and end of their shift to ensure proper calibration.

Small isolated locations that are not large enough to warrant a ULV truck application are easily treated with small handheld ULV sprayers. These units are typically reserved for areas with easy access that can be walked by a technician. Common treatment sites for such handheld applications include used tyre shops or dumps targeting Ae. aegypti and small natural areas targeting freshly emerged Ae. taeniorhynchus to prevent dispersal.

\subsection{Aerial Adulticiding}

The aerial adulticiding operations in Lee County is an important programme designed to efficiently control biting mosquitoes across large geographic areas. LCMCD owns and operates a fleet of eight fixed-wing airplanes outfitted with spray equipment designed to target flying adult mosquitoes (Fig. 12). Adulticiding missions are conducted at night between the hours of 21:00 and 02:00 when night-active mosquitoes are typically most active. Applications are made at an altitude of 350 feet $(107 \mathrm{~m})$ above ground level and pilots are equipped with night vision goggles for maximum visibility. 


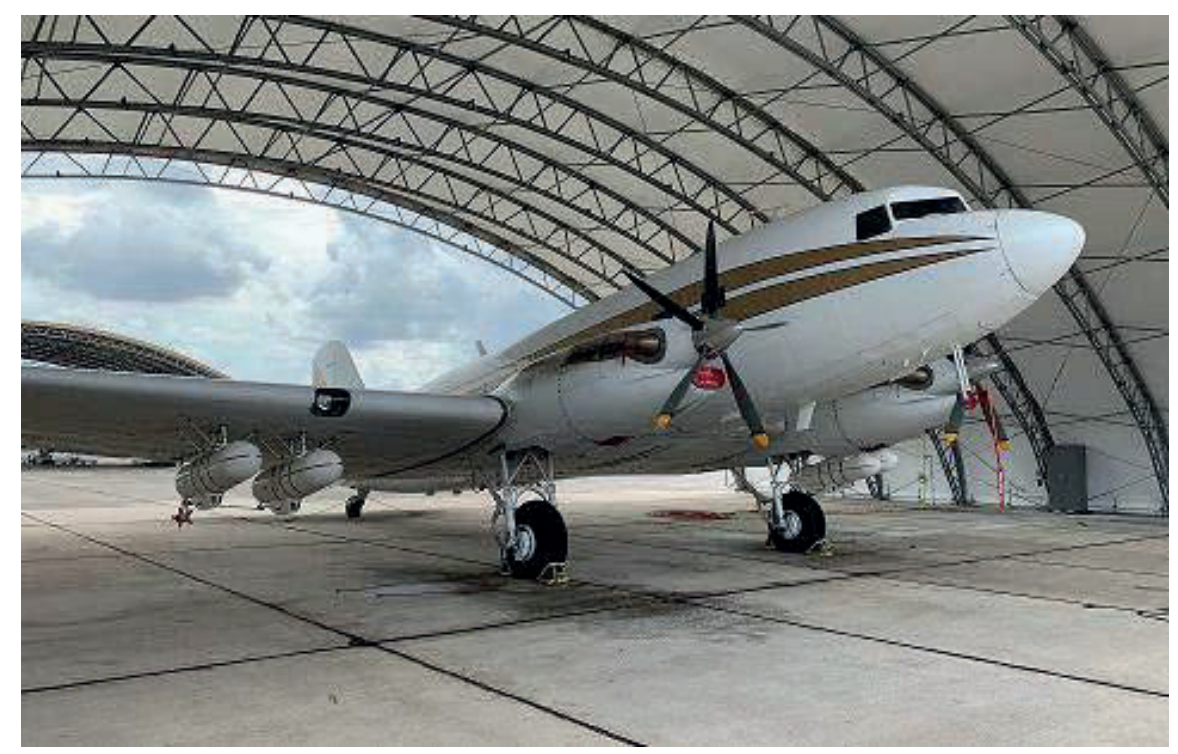

Figure 12. Douglas DC3-TP with four 50-gallon chemical tanks used for aerial adulticiding.

Similar to the LCMCD aerial larviciding system, the adulticiding spray system is controlled via an on-board computer with a pre-programmed mission. Once pilots arrive on-site the spray system is automatically turned on and remains spraying until the pilot exits the treatment area. This automation increases precision of the application and enhances pilot safety when flying in such an unconventional manner. Depending on how large the problematic area is, treatments sites can be as large as 23000 acres per mission per aircraft. Flights typically occur at 130 or 150 knots, depending on aircraft type and chemical flow rate.

LCMCD primarily utilizes naled and malathion for aerial adulticiding. Products are dispensed with a high-pressure nozzle system or with a rotary atomizer at a rate of $0.5 \mathrm{oz} /$ acre, $0.66 \mathrm{oz} / \mathrm{acre}$, or $1.5 \mathrm{oz} /$ acre depending on the pesticide used and the targeted mosquito species. LCMCD does not utilize set treatment frequencies for scheduling treatments of any kind, but rather relies entirely on surveillance data to determine if treatments are warranted. Each surveillance method has an associated treatment threshold that must be met based on inspection type and location baselines.

For an aerial adulticiding treatment to be conducted, surveillance data are evaluated first and considered prior to scheduling. Surveillance methods include landing rate counts, truck trap collections, spray zone thresholds (that were obtained over many years of trap data), arbovirus detection in sentinel chicken flocks, and mosquito trapping results. If criteria mandated by the state of Florida are met and a wide-scale problem is determined, an aerial adulticiding application is scheduled as early as that same night. 


\section{NOVEL TECHNIQUES}

It is essential to keep up with evolving mosquito populations, increasingly sophisticated control technologies, climate change, a constantly increasing human population density, and increases in exotic disease agents and vector invasions. As such, a programme can fall behind and become less efficient than it once was if these changes are not taken into account. To best combat these dynamic circumstances, LCMCD is committed to staying abreast of new technology and the advancement of various control measures.

Applying sterilisation techniques for the control of insect populations is not a new concept, however the application of it on mosquitoes is an emerging field (Lees et al. 2021; Baton et al., this volume). The Sterile Insect Technique (SIT) was first utilized in the late 1950s to successfully control the screwworm fly (Cochliomyia hominivorax Coquerel) on the isolated habitat of Sanibel Island in Lee County, Florida (Bushland and Hopkins 1953; Bushland 1960). Since the first trial on Sanibel Island, the SIT has been employed to effectively suppress, contain and eradicate a variety of medicallyand agriculturally-important insects (Dyck et al. 2021).

LCMCD is currently in the process of establishing the first SIT programme for Ae. aegypti solely operated by a mosquito control district in the state of Florida. This novel programme aims to reduce Ae. aegypti in Lee County using X-ray irradiation for sterilisation. To accomplish this, LCMCD will be mass-rearing locally collected populations of Ae. aegypti, irradiating the mosquitoes using X-rays, and releasing the sterilized male adults on an area-wide basis into the field to breed with wild female populations. The goal of this programme is to become a valuable complement to traditional mosquito control techniques in the fight to prevent the spread of diseases such as Zika, dengue, yellow fever, and chikungunya, which are transmitted via the bite of the Ae. aegypti mosquito.

LCMCD is also interested in using more conventional technology in innovative ways to improve operations. Unmanned aerial systems (UAS) technology has been available to the commercial market for several years now and is utilized primarily for their photographic abilities. LCMCD owns two UAS for the purpose of aiding in inspections of mosquito breeding habitat and have recently purchased one UAS capable of carrying and spraying a payload of insecticide. As the rules and regulations surrounding UAS continue to evolve (Benavente et al., this volume), LCMCD plans on being there along the way to incorporate these new technologies into the mosquito control industry as a part of its commitment to protect the health of the citizens of Lee County.

\section{CONCLUSIONS}

LCMCD operates a comprehensive IMM programme in an effort to provide the most effective mosquito abatement possible for the citizens of Lee County. As with any IMM programme, the efficient integration of all methods together achieves the most advantageous results. 
The larviciding programme, aimed at suppressing mosquitoes in their juvenile life stage, offers the most efficient means of control by targeting mosquitoes when they are at their most concentrated state of development and unable to bite. Source reduction and biological control measures, although varying differently in application, offer a natural and potentially longer duration of control than insecticides.

A strong adulticiding programme plays a vital role in suppressing the biting pressure on the local population and interrupts the disease transmission in the event of an arbovirus outbreak.

The implementation of novel control measures, such as the SIT, complement conventional control methods to aid in the control of disease vectoring agents. All of these methods offer specific advantages, however, if utilized on their own they would prove wildly inadequate. The harmonious integration of all control measures is best supported with a backbone of strong surveillance and a well-educated staff to oversee its implementation.

\section{REFERENCES}

Agramonte, N. M., and C. R. Connelly. 2014. Black salt marsh mosquito Aedes taeniorhynchus (Wiedemann) (Insecta: Diptera: Culicidae). Publication number EENY-591, University of Florida/Institute of Food and Agricultural Sciences Extension.

(AMCA) American Mosquito Control Association. 2017. Best practices for integrated mosquito management: A focused update. Sacramento, California, USA. 58 pp.

Batzer, D. P., and V. H. Resh. 1992. Wetland management strategies that enhance waterfowl habitats can also control mosquitoes. Journal of the American Mosquito Control Association 8: 117-125.

Bibbs, C. S., D. Mathias, and N. Burkett-Cadena. 2019. Dark rice field mosquito Psorophora columbiae (Dyar \& Knab) (Insecta: Diptera: Culicidae). Publication number EENY-735, University of Florida/Institute of Food and Agricultural Sciences Extension.

Bushland, R. C., and D. E. Hopkins. 1953. Sterilisation of screwworm flies with X-rays and gamma rays. Journal of Economic Entomology 46: 648-656.

Bushland, R. C. 1960. Male sterilisation for the control of insects, pp. 1-25. In R. L. Metcalf (ed.), Advances in pest control research, Volume III. Interscience Publishers, New York, NY, USA.

(CABI) Centre for Agriculture and Bioscience International. 2019. Culex quinquefasciatus (southern house mosquito) [original text be D. A. Lapointe]. In Invasive species compendium. Wallingford, UK.

Cassiano, E. J., J. Hill, Q. Tuckett, and C. Watson. 2018. Eastern mosquitofish, Gambusia holbrooki, for control of mosquito larvae. Document FA202, School of Forest Resources, Program in Fisheries and Aquatic Sciences, University of Florida/Institute of Food and Agricultural Sciences Extension.

Challet, G. L. 1994. Mosquito abatement district programs in the United States. The Kaohsiung Journal of Medical Sciences (Gaoxiong Yi Xue Ke Xue Za Zhi) 10 (Supplement): S67-S73.

Connelly, C. R., and D. B. Carlson (eds.). 2009. Florida mosquito control: The state of the mission as defined by mosquito controllers, regulators, and environmental managers. Florida Coordinating Council on Mosquito Control. University of Florida, Institute of Food and Agricultural Sciences, Florida Medical Entomology Laboratory, Vero Beach, Florida, USA. 259 pp.

Day, J. F. 2017. The Florida St. Louis encephalitis mosquito Culex nigripalpus Theobald (Insecta: Diptera: Culicidae). Publication number EENY-10, University of Florida/Institute of Food and Agricultural Sciences Extension.

Day, J. F., and G. A. Curtis. 1999. Blood feeding and oviposition by Culex nigripalpus (Diptera: Culicidae) blood feeding and oviposition before, during and after a widespread St. Louis encephalitis epidemic in Florida. Journal of Medical Entomology 36: 176-181.

Dyck, V. A., J. Hendrichs, and A. S. Robinson (eds.). 2021. Sterile Insect Technique - Principles and practice in Area-Wide Integrated Pest Management. Second Edition. CRC Press, Boca Raton, Florida, USA. $1200 \mathrm{pp}$.

Elmore Jr., C. M., and H. E. Schoof. 1963. Dispersal of Aedes taeniorhynchus Wiedemann near Savannah, Georgia. Mosquito News 23(1): 1-7. 
Focks, D. A., D. A. Dame, A. L. Cameron, and M. D. Boston. 1980. Predator-prey interaction between insular populations of Toxorhynchites rutilus rutilus and Aedes aegypti. Environmental Entomology 9: $37-42$.

Hill, S., and C. R. Connelly. 2009. Southern house mosquito Culex quinquefasciatus Say (Insecta: Diptera: Culicidae). Publication Number EENY-457, University of Florida/Institute of Food and Agricultural Sciences Extension.

Kerzee, K. 2019. The whats and whys of mosquito abatement districts. Midwest Pesticide Action Center.

Kline, D. L. 2006. Mosquito population surveillance techniques. Technical Bulletin of the Florida Mosquito Control Association 6: 2-8.

(LCMCD) Lee County Mosquito Control District. 2019. Lehigh Acres, Florida, USA.

Lees, R. S., D. O. Carvalho, and J. Bouyer. 2021. Potential impact of integrating the Sterile Insect Technique into the fight against disease-transmitting mosquitoes, pp. 1081-1118. In V. A. Dyck, J. Hendrichs, and A. S. Robinson (eds.), Sterile Insect Technique - Principles and practice in Area-wide Integrated Pest Management. Second Edition. CRC Press, Boca Raton, Florida, USA.

McKenna, M. 2016. Disorganized mosquito control will make US vulnerable to Zika. February 29, 2016. National Geographic, Washington, DC, USA.

McDonald, P. T. 1977. Population characteristics of domestic Aedes aegypti (Diptera: Culicidae) in villages on the Kenya coast. II. Dispersal within and between villages. Journal of Medical Entomology 14: 49-53.

Muir, L. E., and B. H. Kay. 1998. Aedes aegypti survival and dispersal estimated by mark-releaserecapture in northern Australia. American Journal of Tropical Medicine and Hygiene 58: 277-282.

Nayar, J. K., and C. R. Connelly. 2017. Mosquito-borne dog heartworm disease. SP486: Pests in and around the southern home. University of Florida/Institute of Food and Agricultural Sciences Extension.

Patterson, G. 2004. The mosquito wars: A history of mosquito control in Florida. University Press of Florida. Gainesville, Florida. 288 pp.

Provost, M. W. 1952. The dispersal of Aedes taeniorhynchus. I. Preliminary studies. Mosquito News 12(3): 174-190.

Provost, M. W. 1969. Man, mosquitoes and birds. The Florida Naturalist 41: 63-67.

Rey, J. R., and C. R. Rutledge. 2006. Mosquito control impoundments. Publication number ENY-648, University of Florida/Institute of Food and Agricultural Sciences Extension.

Rose, A., U. Kröckel, R. Bergbauer, M. Geier, and Á. E. Eiras. 2006. The BG-Sentinel, a novel mosquito trap for research and surveillance. Mitteilungen der Deutschen Gesellschaft für allgemeine und angewandte Entomologie 15: 345-348.

(WHO) World Health Organization. 2016. Monitoring and managing insecticide resistance in Aedes mosquito populations: Interim guidance for entomologists. Geneva, Switzerland.

Zettel, C., and P. Kaufman. 2019. Yellow fever mosquito Aedes aegypti (Linnaeus) (Insecta: Diptera: Culicidae). Publication number EENY-434, University of Florida/Institute of Food and Agricultural Sciences Extension. 